\title{
Prediction of Dynamic Postural Stability During Single-Leg Jump Landings by Ankle and Knee Flexibility and Strength
}

\author{
Valerie J. Williams, Takashi Nagai, Timothy C. Sell, John P. Abt, Russell S. Rowe, \\ Mark A. McGrail, and Scott M. Lephart
}

\begin{abstract}
Context: Dynamic postural stability is important for injury prevention, but little is known about how lower-extremity musculoskeletal characteristics (range of motion [ROM] and strength) contribute to dynamic postural stability. Knowing which modifiable physical characteristics predict dynamic postural stability can help direct rehabilitation and injuryprevention programs. Objective: To determine if trunk, hip, knee, and ankle flexibility and strength variables are significant predictors of dynamic postural stability during single-leg jump landings. Design: Cross-sectional study. Setting: Laboratory Participants: 94 male soldiers (age $28.2 \pm 6.2$ y, height $176.5 \pm 2.6 \mathrm{~cm}$, weight $83.7 \pm 26.0 \mathrm{~kg}$ ). Intervention: None. Main Outcome Measures: Ankle-dorsiflexion and plantar-flexion ROM were assessed with a goniometer. Trunk, hip, knee, and ankle strength were assessed with an isokinetic dynamometer or handheld dynamometer. The Dynamic Postural Stability Index (DPSI) was used to quantify postural stability. Simple linear and backward stepwise-regression analyses were used to identify which physical characteristic variables were significant predictors of DPSI. Results: Simple linear-regression analysis revealed that individually, no variables were significant predictors of the DPSI. Stepwise backward-regression analysis revealed that ankle-dorsiflexion flexibility, ankle-inversion and -eversion strength, and knee-flexion and -extension strength were significant predictors of the DPSI $\left(R^{2}=.19, P=.0016\right.$, adjusted $\left.R^{2}=.15\right)$. Conclusion: Ankle-dorsiflexion ROM, ankle-inversion and -eversion strength, and knee-flexion and -extension strength were identified as significant predictors of dynamic postural stability, explaining a small amount of the variance in the DPSI.
\end{abstract}

Keywords: musculoskeletal, |Army|

Postural stability is the ability to maintain the body in equilibrium by keeping the center of mass within the base of support. Maintaining postural stability requires the integration of sensory information and execution of appropriate motor responses. Postural stability can be measured with static tests or dynamic tests. Static tests use a fixed, firm, unmoving base of support, while dynamic tests use movements requiring a change in position or location. ${ }^{1-3}$ Prospective studies have demonstrated that impaired static postural stability is a risk factor for ankle and leg injuries. ${ }^{4-6}$ However, static tests may not be the best choice for athletes, who may have higher balance ability, requiring a shift toward using dynamic postural-stability tests. The rationale for using dynamic postural-stability tests is that they are more challenging and similar to athletic activity. Furthermore, there is a poor relationship between static and dynamic postural stability, indicating they may measure different aspects of postural stability. ${ }^{7}$

Williams, Nagai, and Sell are with the Warrior Human Performance Research Laboratory, University of Pittsburgh, Pittsburgh, PA. Abt and Rescin Lephart are with the College of Healh Sciences, University of Kentucky, Lexington KY. Rowe is with the Carl R. Darnall Army Medical Center, Fort Hood, TX. McGrail is with the Office of the Surgeon General, Dept of the Army, Washington DC. Address author correspondence to Timothy Sell at tcs15@pitt.edu.
There are 2 ways of testing dynamic postural stability. One way is when the base of support stays in 1 place and the subject moves within that base of support, an example being the Star Excursion Balance Test (SEBT). The SEBT requires the subject to maintain balance while completing purposeful single-leg movements without changing the location of the base of support, and it has been found to be predictive of lowerextremity injury. ${ }^{8}$ Another way to test dynamic postural stability is by having subjects change the location of the base of support and maintain their postural stability, as with single-leg jump landings. ${ }^{3}$ Postural stability is then quantified with the Dynamic Postural Stability Index (DPSI), which measures the variability in ground-reaction forces (GRFs) on landing. The use of single-leg jump landings is advantageous because they place additional demands on the neuromuscular system, closely replicate athletic tasks, and are a common lower-extremity-injury mechanism, although the ability of the DPSI to predict lower-extremity injury has not been established. 3,9

After an injury, it is recommended that rehabilitation programs focus on restoring ankle flexibility and joint range of motion, as well as lower-extremity and trunk strength, before athletes return to play in attempt to avoid reinjury. Previous research has demonstrated that intervention programs incorporating flexibility and strength
Commented [JG1]: Please provide 1 or 2 more

Page 1 of 7 
training of the lower extremity and trunk are capable of improving dynamic postural stability, ${ }^{12,13}$ as well as reducing injury in athletes. ${ }^{14-16}$ When looking at dynamic tasks, adequate lower-extremity strength is required for performance of single-leg jump landings. ${ }^{17}$ Those studies, however, did not determine which trunk, hip, knee, and ankle motion and strength variables predict dynamic posturalstability performance. Previously, we demonstrated that peak GRFs, hip-flexion angle at the time of foot contact, and hip-abduction peak torque predicted DPSI. ${ }^{18}$ For this study we wanted to include lower-extremity predictor variables that could be targeted with strength and rangeof-motion interventions. Based on previous literature, we believed it would be important to include ankle range of motion because ankle dorsiflexion is a risk factor for ankle sprains, ${ }^{6,19}$ and improving ankle range of motion and strength decreased risk of falling in older adults. ${ }^{20}$ In addition, knee-extensor strength has been found to be a significant predictor of static and dynamic balance in the elderly. ${ }^{21}$ Literature on trunk strength indicates that trunkextensor-muscle performance (strength and endurance) is associated with static-balance scores in elderly individuals with limited mobility, ${ }^{22}$ and that core-strengthening programs improve static postural stability, ${ }^{23}$ as well as dynamic postural stability measured with the SEBT. ${ }^{12,24}$

We believe that it is important to simultaneously investigate physical characteristics as predictors of dynamic postural stability measured with the DPSI after single-leg jump landings in our population of interest (young active male military). The purpose of this study was to identify which trunk and lower-extremity variables are significant predictors of dynamic postural stability during single-leg jump landings. We hypothesized that trunk, hip, knee, and ankle strength, as well as ankle range of motion, would be identified as significant predictors of dynamic postural stability. Identifying these physical characteristics will help direct clinicians in choosing appropriate interventions to improve strength and range of motion in areas contributing to dynamic postural stability.

\section{Methods}

\section{Design}

This was a cross-sectional study. Subjects' ankle range of motion, lower-extremity and trunk strength, and dynamic postural stability were collected. Testing was performed over 2 days separated by approximately 1 week as dictated by the protocol for a larger ongoing study. Only the dominant-limb data will be presented herein. Limb dominance was defined as the leg used to kick a ball maximally.

\section{Participants}

Ninety-four male subjects (age $28.2 \pm 6.2 \mathrm{y}$, height 176.5 $\pm 2.6 \mathrm{~cm}$, and weight $83.7 \pm 26.0 \mathrm{~kg}$ ) were recruited from the Army 101st Airborne Division (Air Assault) to participate in this study. Subjects had an average of $4.5 \pm$ 3.4 years (range $1-12$ ) of active service, and were 18 to 45 years old with no history of concussion or mild head injury in the previous year; no musculoskeletal pathologies to the upper, lower, or back regions in the past 3 months; and no history of neurological or balance disorders. All subjects were cleared for active duty, without any prescribed duty restrictions. This study was part of an ongoing project focusing on injury prevention and performance optimization in the 101st Airborne Division (Air Assault). Human-subject-protection approvals were obtained from the institutional review boards of the University of Pittsburgh and the Dwight D. Eisenhower Army Medical Center.

\section{Procedures}

Active dorsiflexion and plantar flexion were measured with the knee bent as described by Norkin and White. ${ }^{25} \mathrm{~A}$ total of 3 measurements were taken for each test and averaged for data analyses. A standard goniometer was used to measure ankle angle of motion (Saunders Group, Chaska, MN).

Strength of the trunk, hips, and knees was assessed using the Biodex Multi-Joint System 3 Pro (Biodex Medical Systems, Inc, Shirley, NY). Subjects were given verbal instructions, stabilized according to the manufacturer's guidelines, and provided practice trials $(3$ repetitions at $50 \%$ effort and 3 repetitions at maximal effort) to ensure familiarity with the strength-testing procedures. They were provided a 1-minute rest period between practice trials and test trials to prevent fatigue. Subjects performed 5 reciprocal concentric isokinetic test trials at $60 \%$ for trunk flexion/extension and knee flexion/extension. They were instructed to complete the 5 repetitions as hard and as fast as they could, but actual time to completion varied among subjects depending on their effort and ability. These methods for measuring isokinetic strength at the knee have ICCs ranging from .93 to $.98 .^{26}$ Unpublished data from our laboratory demonstrate ICCs of .92 to .98 for the trunk measurements. Isometric hip-abduction strength was tested in the side-lying, hip-neutral position on the Biodex. Subjects completed three 5-second hip-abduction isometric contractions. These methods have ICCs of .64 to $.85 .^{27}$ Ankle strength was assessed with a handheld dynamometer (Lafayette Instrument Co, Lafayette, IN). Ankle testing was completed with a handheld dynamometer, as opposed to the Biodex, due to limited ability of the ankle attachment to stabilize the foot and lower leg, limited ability to perform motion in the plane of motion of the ankle joint, and lack of availability of ankle attachments at multiple remote locations. Testing was performed in a seated position based on traditional manual muscle-strength-testing hand placement. Three trials were performed for each movement and averaged for analyses. Similar methods using a handheld dynamometer have reported ICCs of .74 to $.84 .^{28}$

Dynamic postural stability was assessed with a force plate (Kistler 9286A, Amherst, NY) at a sampling frequency of $1200 \mathrm{~Hz}$ during a single-leg jump landing and was using single-leg jump landings in the anterior 
direction (Figure 1). Our methods were adapted from Wikstrom et $\mathrm{al}^{3}$ and Sell et $\mathrm{al}^{7}$ and have an ICC of .86 The single-leg jump-landing task used in this study normalized the jump distance according to body height. Subjects were positioned $40 \%$ of their body height away from the edge of a force plate, and a $30-\mathrm{cm}$ hurdle was placed at the midpoint between the starting position and the force plate. Jumps were normalized to height rather than distance to minimize equipment needed at the remote testing site, as well as other remote sites where the same procedures were planned to be used. Subjects were instructed to jump over the hurdle in the anterior direction from 2 feet, landing on the force plate with the test leg. They were asked to stabilize as quickly as possible, place their hands on their hips, and remain balanced for 10 seconds while looking forward. A total of 3 successful trials were collected and averaged for analyses. Subjects were provided a minimum of 3 practice trials to become familiar with the single-leg jump-landing task. Trials were discarded and repeated if subjects failed to jump over or came in contact with the hurdle, the hopped on the test leg after landing, the nontest leg touched down on the force plate or the ground surrounding the force plate, or they removed hands from their hips for longer than 5 seconds. A 1minute rest period was provided between trials to prevent fatigue.

$1<<<<<<<<<<<<<$ FIGURE 1 1 $>>>>>>>>>>>1$

For all strength measures performed on the Biodex Multi-Joint System 3 Pro, the average peak torque $(\mathrm{Nm})$ of the 5 repetitions was normalized to body mass in kilograms ( $\%$ body weight). For strength measurements performed with handheld dynamometer, the subject performed three 5-second maximal isometric contractions against the dynamometer measured in kilograms, which were averaged for analyses and normalized to body weight in kilograms ( $\%$ body weight). For all of the flexibility variables, the average of 3 trials was used for analyses. To quantify dynamic postural stability, forceplate data were passed through an amplifier and analog-todigital board (DT3010, Digital Translation, Marlboro, MA) and stored on a personal computer. A custom MATLAB (v7.0.4, Natick, MA) script was used to process the GRF data for calculating the DPSI. GRF data were passed through a zero-lag fourth-order low-pass Butterworth filter with a frequency cutoff of $20 \mathrm{~Hz}$. The description of calculation of the DPSI has been published elsewhere. $^{3}$ While multiple DPSI calculations are available, we chose this equation to be consistent across multiple studies being completed by our research group, including a reliability study of our methods. Briefly, the DPSI is a composite of the anteroposterior, mediolateral, and vertical GRFs. The first 3 seconds after initial contact was used to calculate the DPSI. Initial contact was defined as the instant the vertical GRF exceeded 5\% body weight.

\section{Statistical Analysis}

The dependent variable was the DPSI score, and the independent variables were ankle range of motion and the lower-extremity strength variables. Means and standard deviations were calculated for each variable. The variables and residuals were assessed for normality using the Shapiro-Wilk test $(\underline{\alpha}=.05)$, histograms, scatter plots, and $\mathrm{Q}-\mathrm{Q}$ plots. For the regression analysis, the variables were assessed for homoscedasticity using the Breusch-Pagan test $(\alpha=.05)$ and multicollinearity using the varianceinflation-factor (VIF) method (VIF $<10$ ).

To determine the relationship between the DPSI and the independent variables, Pearson product-moment correlations were computed. Simple linear-regression analysis was performed to determine individual predictors of dynamic postural stability. To find the best combination of physical characteristics that predict dynamic postural stability, backward stepwise regression was used. The independent variables were allowed to enter (probability $=.10$ ) and removed (probability $=.20$ ) at every step to identify the final regression model. This method demonstrated which variables were the most predictive of DPSI performance. The level of statistical significance was set at .05 a priori for all analyses. All statistical analyses were performed with STATA 11 (StataCorp LP, College Station, TX).

\section{Results}

The means and standard deviations for all variables are presented in Table 1. The Shapiro-Wilk test found that all variables were normally distributed $(P>.05)$. All histograms and residual scatter plots supported the normality assumption, as well. The Breusch-Pagan test supported homoscedasticity of the variables $\left(\chi^{2}=0.71, P\right.$ $=.40)$. VIF analyses supported no multicollinearity being present $(\mathrm{VIF}<10)$

$1<<<<<<<<<<<<<$ TABLE 1 1 $>>>>>>>>>>>1$

All of the range-of-motion and strength variables had little correlation (rho $<0.25$ ) with the DPSI score. ${ }^{29}$ Furthermore, the results of simple linear regression between each variable and DPSI score showed that, individually, none of the variables were significant predictors. No 1 variable alone was able to explain the variance in the DPSI score. The backward stepwise-regression results are displayed in Tables 2 and 3 . This regression model identified ankle-dorsiflexion range of motion, ankleinversion/eversion strength, and knee-flexion/extension strength as important predictors of the DPSI $\left(R^{2}=.19, P=\right.$ .0016). Ankle-plantar-flexion range of motion, hipabduction strength, and torso-flexion/extension strength were removed from the model. The adjusted $R^{2}$ for this model was .15 , indicating that approximately $15 \%$ of the variance in the DPSI score was explained by ankledorsiflexion range of motion, ankle-inversion/eversion strength, and knee-flexion/extension strength.

$1<<<<<<<<<<<<<$ TABLE $2>>>>>>>>>>>1$

$1<<<<<<<<<<<<<<$ TABLE $3>>>>>>>>>>>1$ 


\section{Discussion}

The purpose of this study was to determine if lowerextremity range of motion and trunk and lower-extremity strength variables were important predictors of dynamic postural stability during single-leg jump landings. The final model included ankle-dorsiflexion range of motion, ankle-inversion/eversion strength, and kneeflexion/extension strength as significant predictors of dynamic postural stability, but not ankle-plantar-flexion, trunk, or hip strength. The variables included in the final model are supported by previous literature, which has found ankle dorsiflexion to be important for balance and demonstrated a significant relationship between greater knee and ankle strength and higher dynamic postural stability in the elderly. ${ }^{20,21,30}$

It is interesting to note that, individually, each independent variable failed to predict dynamic postural stability, but the combination of variables identified by the final model explains a small amount of the variance in the DPSI score when considered in combination. No single measure from the current data set predicts dynamic postural stability, but there may be a single measure not captured in this study. This suggests that multiple variables work together to contribute to dynamic postural stability and that there is not a singular physical characteristic that will predict performance. Another reason we may have found that this specific group of physical characteristics predicts DPSI score, but not any single characteristic, is that we are studying healthy, active individuals in the military without any curren injury or major strength or range-of-motion deficits. Furthermore, we do not expect our population of male military personnel to have poor postural stability. This is in contrast to other literature that has studied injured or elderly populations. In those groups, 1 individual strength or range-of-motion variable that is impaired may have a greater effect on dynamic postural stability.

To further explain the variables included in the final model, we think that since the muscles of the ankle and knee were found to be important in predicting DPSI score, but not the more proximal muscle groups of the trunk and hip, our study suggests that perhaps this distal musculature is most important in stabilizing the lower extremity on single-leg landing from a jump. Theoretically, we think more distal lower-extremity characteristics may predict DPSI performance because of their relationship with dissipating GRFs and stabilizing lower-extremity joints on landing. Ankle-dorsiflexion range of motion, but not plantar flexion, was found to be a predictor of the DPSI score. This is likely because adequate dorsiflexion range of motion is essential for dissipating GRFs during landing tasks from various heights. Soft landings (less GRF) used greater range of motion than stiff landings (higher GRF). ${ }^{31}$ Because of how GRFs are used in calculation of the DPSI score, landing with a softer landing (decreased vertical GRF) can occur with a lower (better) DPSI score. ${ }^{3}$ To incorporate strength into this explanation, previous research has found that, during drop-landing tasks, greater eccentric work was performed by the ankle and knee musculature during soft landings than with hard landings. ${ }^{31}$ During single-leg jump landings, the lower-extremity musculature functions to decelerate and stabilize the body's center of mass. ${ }^{32}$ Furthermore, we think that increased strength at the knee and ankle was found to be an important predictor because it contributes to increased muscle stiffness. Increased muscle stiffness increases proprioceptor sensitivity to stretch and reduces the electromechanical delay from the muscle-spindle stretch reflex, adding stability to the joint. ${ }^{33,34}$ Strength of the muscles on both sides of the ankle and knee joints will help stabilize each of these joints when landing. If the joints are more stable on landing, perhaps that is why dynamic postural stability is better. With this particular task, the knee and ankle musculature have been found to be the most important, rather than the more proximal musculature.

In the current study, hip-abduction, trunk-flexion, and trunk-extension strength were not significant predictors of dynamic postural stability. We thought that hip and trunk strength would be predictors of the DPSI because they would help stabilize the lower extremity proximally by controlling knee and ankle position. Several studies have investigated the effect of core-strengthening programs on postural-stability performance. When comparing our study with this literature it is important to note that while those studies used training programs targeting the muscles measured in our study, they did not directly measure strength of the trunk musculature. Dynamic balance did improve in some studies, but we do not know the baseline trunk strength of the subjects or if their trunk strength improved after training. Some research suggests that core strengthening increases postural stability in subjects with low back pain and in sedentary individuals. ${ }^{23,35,36}$ It is possible that trunk strength is not a significant predictor of dynamic postural stability in this population because they had adequate trunk strength, were not experiencing low back pain, and were physically active.

Studies looking at the effect of core-muscle training on dynamic balance using the SEBT have found that corestabilization exercises, but not traditional corestrengthening exercises, improve dynamic balance. ${ }^{24}$ Another study that included core-strengthening exercises, lower-extremity strengthening, and agility exercises reported increases in SEBT performance after training. ${ }^{12}$ In contrast, other work did not find that a core-strengthtraining program that included exercises for the trunk flexors, trunk extensors and hip extensors improved SEBT performance. ${ }^{37}$ These varying results indicate that the type of training program chosen to strengthen the core is important and that performance is likely related to multiple factors rather than just strength alone. All of these studies used the SEBT, which is different from the task in our study. Subjects performing the SEBT stand in 1 place on 1 leg while reaching in different directions with the other leg. The test does not measure stabilization after landing from a jump. Because of the different physical 
requirements of the tasks, single-leg jump landings and the SEBT are likely measuring different components of dynamic postural stability. Our study suggests that these different tasks have different physical requirements that predict performance.

Our study design and methods have several limitations. Only healthy adult male soldiers were included in this study; therefore, our results cannot be generalized to women or injured populations. Because there are potential differences in strength, ankle range of motion, and DPSI scores in women and injured groups, the relationship among these variables in those groups should be studied. Our study population were healthy men, so it is possible that in individuals with decreased strength or postural stability, or injury, there may be a stronger relationship found. In addition, there may be flexibility and strength variables important to dynamic postural stability that were not assessed in this study. We did not give specific instructions for jumping over the hurdle beyond jumping with 2 feet and landing on 1 . It is likely that subjects used various movement patterns to jump over the hurdle and land on the force plate. Future research should explore the relationship between kinematic variables and dynamic postural stability during single-leg jump landings. The strategies used during the jump and during the landing may explain additional variance in the DPSI score.

Jump landings are a common mechanism of injury in athletics and are commonly used in the laboratory setting to assess dynamic postural stability. Identifying physical characteristics that predict dynamic-posturalstability performance has clinical implication for injuryprevention and rehabilitation-training programs. The findings of our study indicate that ankle-dorsiflexion range of motion, ankle strength, and knee strength predict performance on the DPSI score after an anterior single-leg jump landing. Even though their contribution may be small in a healthy male military population, making small improvements can be important, since the subjects are not impaired at baseline. Physical training programs for performance in individuals who require dynamic postural stability when executing single-leg jumps in the anterior direction should include exercises to improve ankle dorsiflexion and strengthening for ankle inversion/eversion, as well as knee flexion/extension. This model could also potentially be incorporated into rehabilitation. Once the specific impairments and deficits of the patient have been addressed, these physical characteristics could be included to improve performance before discharge from therapy.

\section{Conclusions}

The results indicate that ankle-dorsiflexion flexibility, ankle-inversion/eversion strength, and kneeflexion/extension strength are significant predictors of dynamic postural stability during single-leg jump landings. These results are clinically relevant, as clinicians should incorporate these flexibility and strength variables into injury-prevention and rehabilitation-training programs in attempt to mitigate lower-extremity injuries. Some of the variables that are predictive of dynamic postural stability are also proposed risk factors of injury but have not definitively been shown to reduce injury risk. Furthermore, there are likely additional variables that significantly predict dynamic postural stability during single-leg jump landings, particularly kinematic variables, that should be considered when developing intervention programs. Future research should continue to explore variables that are significant predictors of dynamic postural stability during single-leg jump landings, as well as in patients with known pathologies.

\section{Acknowledgments}

This work was supported by the US Army Medical Research and Materiel Command under Award No W81XWH-06-2-0070/ W81XWH-09-2-0095/W81XWH-11-2-0097. Opinions, interpretations, conclusions, and recommendations are those of the authors and are not necessarily endorsed by the US Army.

\section{References}

1. Goldie PA, Bach TM, Evans OM. Force platform measures for evaluating postural control: reliability and validity. Arch Phys Med Rehabil. 1989;70(7):510517. PubMed

2. Riemann BL, Caggiano NA, Lephart SM. Examination of a clinical method of assessing postural control during a functional performance task. J Sport Rehabil. 1999;8(3):171-183.

http://dx.doi.org/10.1123/jsr.8.3.171

3. Wikstrom EA, Tillman MD, Smith AN, Borsa PA. A new force-plate technology measure of dynamic postural stability: the Dynamic Postural Stability Index. J Athl Train. 2005;40(4):305-309. PubMed

4. Söderman K, Alfredson H, Pietila T, Werner S. Risk factors for leg injuries in female soccer players: a prospective investigation during one out-door season. Knee Surg Sports Traumatol Arthrosc. 2001;9(5):313321. PubMed doi:10.1007/s001670100228

5. McGuine TA, Greene JJ, Best T, Leverson G. Balance as a predictor of ankle injuries in high school basketball players. Clin J Sport Med. 2000;10(4):239-244.

6. Willems TM, Witvrouw E, Delbaere K, Mahieu N, De Bourdeaudhuij I, De Clercq D. Intrinsic risk factors for inversion ankle sprains in male subjects: a prospective study. Am J Sports Med. 2005;33(3):415-423. PubMed doi: $10.1177 / 0363546504268137$

7. Sell TC, House AJ, Abt JP, Huang HC, Lephart SM. An examination, correlation, and comparison of static and dynamic measures of postural stability in healthy, physically active adults. Phys Ther Sport. 2012;13(2): 80-86. PubMed doi:10.1016/j.ptsp.2011.06.006

8. Gribble PA, Hertel J, Plisky P. Using the Star Excursion Balance Test to assess dynamic posturalcontrol deficits and outcomes in lower extremity injury: a literature and systematic review. J Athl Train. 2012;47(3):339-357. PubMed

9. Wikstrom EA, Tillman MD, Schenker S, Borsa PA. Failed jump landing trials: deficits in neuromuscular 
control. Scand J Med Sci Sports. 2008;18(1):55-61. PubMed doi:10.1111/j.1600-0838.2006.00629.x

10. Bahr R, Karlsen R, Lian O, Ovrebo RV. Incidence and mechanisms of acute ankle inversion injuries in volleyball: a retrospective cohort study. Am J Sports Med. 1994;22(5):595-600. doi: $10.1177 / 036354659402200505$

$\underline{\text { PubMed }}$

Dick R, Hertel J, Agel J, Grossman J, Marshall SW. Descriptive epidemiology of collegiate men's basketball injuries: National Collegiate Athletic Association Injury Surveillance System, 1988-1989 through 20032004. J Athl Train. 2007;42(2):194-201. PubMed

12. Filipa A, Byrnes R, Paterno MV, Myer GD, Hewett TE. Neuromuscular training improves performance on the Star Excursion Balance Test in young female athletes. J Orthop Sports Phys Ther. 2010;40(9):551558. PubMed doi:10.2519/jospt.2010.3325

13. Hale SA, Hertel J, Olmsted-Kramer LC. The effect of a 4-week comprehensive rehabilitation program on postural control and lower extremity function in individuals with chronic ankle instability. J Orthop Sports Phys Ther. 2007;37(6):303-311. PubMed doi:10.2519/jospt.2007.2322

14. Emery CA, Meeuwisse WH. The effectiveness of a neuromuscular prevention strategy to reduce injuries in youth soccer: a cluster-randomised controlled trial. $\mathrm{Br}$ $J \quad$ Sports Med. 2010;44:555-562. PubMed doi: $10.1136 /$ bjsm.2010.074377

15. Olsen OE, Myklebust G, Engebretsen L, Holme I, Bahr R. Exercises to prevent lower limb injuries in youth sports: cluster randomised controlled trial. BMJ. 2005; 330(7489):449. doi:10.1136/bmj.38330.632801.8F

6. Pasanen $\mathrm{K}$, Parkkari J, Pasanen $\mathrm{M}$, et al. Neuromuscular training and the risk of leg injuries in female floorball players: cluster randomised controlled study. BMJ. 2008;337:a295. PubMed

17. Johnston RB, 3rd, Howard ME, Cawley PW, Losse GM. Effect of lower extremity muscular fatigue on motor control performance. Med Sci Sports Exerc. 1998;30(12):1703-1707. PubMed doi:10.1097/00005768-199812000-00008

18. House AJ, Nagai T, Deluzio JB, et al. Landing impact, hip kinematics, and hip strength predict dynamic postural stability in Army 101st Airborne. Paper presented at: American College of Sports Medicine Annual Meeting; June 2, 2010; Baltimore, MD doi:10.1249/01.MSS.0000384394.99058.fd

19. Kofotolis N, Kellis E. Ankle sprain injuries: a 2-year prospective cohort study in female Greek professional basketball players. J Athl Train. 2007;42(3):388-394. PubMed

20. Schwenk M, Jordan ED, Honarvararaghi B, Mohler J, Armstrong DG, Najafi B. Effectiveness of foot and ankle exercise programs on reducing the risk of falling in older adults: a systematic review and meta-analysis of randomized controlled trials. $\mathrm{J} \mathrm{Am}$ Podiatr Med Assoc. 2013;103(6):534-547. PubMed doi: $10.7547 / 1030534$

21. Carter ND, Khan KM, Mallinson A, et al. Knee ex tension strength is a significant determinant of static and dynamic balance as well as quality of life in older community-dwelling women with osteoporosis. Gerontology. 2002;48(6):360-368. PubMed doi: $10.1159 / 000065504$

22. Suri P, Kiely DK, Leveille SG, Frontera WR, Bean JF. Trunk muscle attributes are associated with balance and mobility in older adults: a pilot study. PM R. 2009; 1(10):916-924. doi:10.1016/j.pmrj.2009.09.009

PubMed

23. Kaji A, Sasagawa S, Kubo T, Kanehisa H. Transient effect of core stability exercises on postural sway during quiet standing. $J$ Strength Cond Res. 2010;24(2):382-388.

24. Imai A, Kaneoka K, Okubo Y, Shiraki H. Effects of two types of trunk exercises on balance and athletic performance in youth soccer players. Int J Sports Phys Ther. 2014;9(1):47-57. PubMed

25. Norkin CC, White DJ. Measurement of Joint Motion: A Guide to Goniometry. 2nd ed. F.A. Davis; 1995.

26. Keskula DR, Dowling JS, Davis VL, Finley PW, Dell'omo DL. Interrater reliability of isokinetic measures of knee flexion and extension. J Athl Train. 1995;30(2):167-170. PubMed

27. Sell TC, Tsai YS, Smoliga JM, Myers JB, Lephart SM. Strength, flexibility, and balance characteristics of highly proficient golfers. $J$ Strength Cond Res. 2007;21(4):1166-1171.

28. Kelln BM, McKeon PO, Gontkof LM, Hertel J. Handheld dynamometry: reliability of lower extremity muscle testing in healthy, physically active, young adults. J Sport Rehabil. 2008:17(2):160-170. PubMed http://dx.doi.org/10.1123/jsr.17.2.160

29. Portney LG, Watkins MP. Foundations of Clinical Research: Applications to Practice. 2nd ed. Upper Saddle River, NJ: Prentice Hall; 2000.

30. Kligyte I, Lundy-Ekman L, Medeiros JM. Relationship between lower-extremity muscle strength and dynamic balance in people poststroke [in Spanish]. Medicina (B Aires). 2003;39(2):122-128.

31. Zhang SN, Bates BT, Dufek JS. Contributions of lower extremity joints to energy dissipation during landings. Med Sci Sports Exerc. 2000;32(4):812-819. PubMed doi:10.1097/00005768-200004000-00014

32. Devita P, Skelly WA. Effect of landing stiffness on joint kinetics and energetics in the lower extremity. Med Sci Sports Exerc. 1992;24(1):108-115. PubMed doi: 10.1249/00005768-199201000-00018

33. Riemann BL, Lephart SM. The sensorimotor system, part I: the physiologic basis of functional joint stability. J Athl Train. 2002;37(1):71-79. PubMed

34. Blackburn T, Guskiewicz KM, Petschauer MA, Prentice WE. Balance and joint stability: the relative contributions of proprioception and muscular strength. $J$ Sport Rehabil. 2000;9(4):315-328. http://dx.doi.org/10.1123/jsr.9.4.315

35. Carpes FP, Reinehr FB, Mota CB. Effects of a program for trunk strength and stability on pain, low back and pelvis kinematics, and body balance: a pilot study. $J$ Bodyw Mov Ther. 2008;12(1):22-30. PubMed doi:10.1016/j.jbmt.2007.05.001

36. Cosio-Lima LM, Reynolds KL, Winter C, Paolone V, Jones MT. Effects of physioball and conventional floor
Commented [JG4]: Where was this published?

Commented [FS2]: Reference has only first page number. Please provide the last page number if article is longer than one page. (in reference 15 "Olsen, Myklebust, Engebretsen, Holme, Bahr, 2005").

Commented [FS3]: Reference has only first page number. than one page. (in reference 16 "Pasanen, Parkkari, Pasanen, et al, 2008"). 
exercises on early phase adaptations in back and abdominal core stability and balance in women. $J$ Strength Cond Res. 2003;17(4):721-725.

37. Sato K, Mokha M. Does core strength training influence running kinetics, lower-extremity stability, and $5000-\mathrm{m}$ performance in runners? J Strength Cond Res. 2009;23(1):133-140.

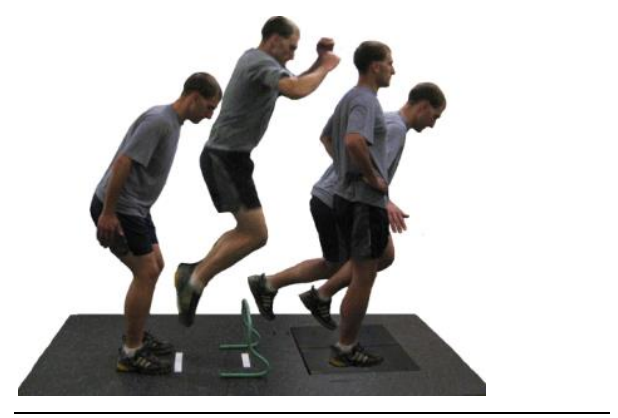

Figure 1 - Anterior single-leg jump landing.

Table 1 Dependent and Independent Variables, $N=94$

\begin{tabular}{lccc} 
Variable & Mean \pm SD & Minimum & Maximum \\
\hline $\begin{array}{l}\text { Dynamic Postural Stability Index } \\
\text { Range of motion }\end{array}$ & $0.38 \pm 0.05$ & 0.24 & 0.49 \\
$\quad$ & & & \\
ankle dorsiflexion $\left({ }^{\circ}\right)$ & $17.22 \pm 7.26$ & 1.33 & 34.33 \\
$\quad$ ankle plantar flexion $\left({ }^{\circ}\right)$ & $51.38 \pm 8.26$ & 35.67 & 78.00 \\
$\begin{array}{l}\text { Strength } \\
\text { trunk flexion (\% bodyweight) }\end{array}$ & $197.87 \pm 46.28$ & 73.60 & 307.69 \\
trunk extension (\% bodyweight) & $335.95 \pm 85.34$ & 163.00 & 557.74 \\
hip abduction (\% bodyweight) & $162.50 \pm 33.65$ & 76.17 & 262.65 \\
knee flexion (\% bodyweight) & $114.71 \pm 23.72$ & 56.41 & 175.64 \\
knee extension (\% bodyweight) & $227.91 \pm 40.46$ & 104.87 & 317.91 \\
ankle inversion (\% bodyweight) & $32.71 \pm 9.19$ & 12.13 & 52.80 \\
ankle eversion (\% bodyweight) & $27.11 \pm 6.07$ & 8.20 & 43.40 \\
\hline
\end{tabular}

Table 2 Stepwise-Regression Model Predicting Dynamic Postural Stability

\begin{tabular}{lccc}
\hline Source & SS & $d f$ & MS \\
\hline Model & 0.0363 & 5 & 0.0073 \\
Residual & 0.1501 & 88 & 0.0017 \\
Total & 0.1865 & 93 & 0.002 \\
\hline
\end{tabular}

Note: Based on 94 observations. $F_{5,88}=4.26$, probability $>F=.0016, R^{2}=.19$, adjusted $R^{2}=.15$

Table 3

\begin{tabular}{lccc}
\hline Variable & Coefficient & $t$ & $P$ \\
\hline Ankle-dorsiflexion range of motion $\left(^{\circ}\right)$ & -.0097 & -1.63 & .108 \\
Ankle-inversion strength $(\mathrm{kg})$ & -.0017 & -2.69 & .009 \\
Ankle-eversion strength $(\mathrm{kg})$ & .0030 & 3.19 & .002 \\
Knee-flexion strength $(\%$ body weight) & -.0006 & -2.32 & .023 \\
Knee-extension strength (\% body weight) & .0004 & -2.69 & .004 \\
Constant & .3399 & 11.03 & .000
\end{tabular}

